\title{
Countrywide serological evaluation of canine prevalence for Anaplasma spp., Borrelia burgdorferi (sensu lato), Dirofilaria immitis and Ehrlichia canis in Mexico
}

Rebeca Movilla ${ }^{1 *}$, Carlos García ${ }^{2}$, Susanne Siebert ${ }^{3}$ and Xavier Roura ${ }^{1}$

\begin{abstract}
Background: Canine vector-borne diseases (CVBD) have become a major concern for canine and human public health. The aim of the study described here is to add epidemiological data regarding four pathogens responsible for CVBD, namely anaplasmosis, borreliosis, dirofilariosis and ehrlichiosis in a national survey conducted in Mexico.

Methods: Seventy-four veterinary centres located in 21 federal Mexican states were asked to test dogs with clinical signs suspect for CVBD and healthy dogs, for detection of Dirofilaria immitis antigen and antibodies against Anaplasma spp., Borrelia burgdorferi (sensu lato) and Ehrlichia canis using the SNAP® 4DX ${ }^{\circledast}$ from IDEXX ${ }^{\circledR}$ Laboratories.

Results: A total of 1706 dogs were tested, including 943 apparently healthy and 722 CVBD-suspect dogs. Infected dogs were $36.7 \%$. The highest percentages of infection with E. canis (51.0\%) and Anaplasma spp. (16.4 \%) were obtained in the northwestern region, while D. immitis was most frequently found in the northeastern region of the country (8.9\%). Four dogs from the northwestern, northeastern, eastern and southeastern regions, respectively, were positive for B. burgdorferi (sensu lato). Northcentral regions showed lowest overall prevalence of infection (2.4\%). Co-infections were detected in $8.8 \%$ of the dogs tested. Statistically significant lower positivity was found among dogs aged less than one year (23.2\%) and small-sized dogs (27.6\%), while higher prevalence of infection was found in dogs living outdoors (42.0\%), dogs with detectable tick infestation (43.3\%) and dogs that received treatment for tick-transmitted infections (58.8\%). Seropositivity was a risk factor for the presence of clinical signs as follows: Anaplasma spp. $(\mathrm{OR}=2.63 ; 95 \% \mathrm{Cl}: 1.88-3.67 ; P<0.0001)$, D. immitis $(\mathrm{OR}=2.52 ; 95 \% \mathrm{Cl}: 1.61-3.95 ; P<0$. 0001), E. canis $(\mathrm{OR}=3.58 ; 95 \% \mathrm{Cl}: 2.88-4.45 ; P<0.0001)$, mixed infections $(\mathrm{OR}=4.08 ; 95 \% \mathrm{Cl}: 2.79-5.96 ; P<0.0001)$, one or more agents $(\mathrm{OR}=3.58 ; 95 \% \mathrm{Cl}: 2.91-4.42 ; P<0.0001)$.

Conclusions: Canine serological evidence supports that dogs from Mexico are at risk of acquiring Anaplasma spp., D. immitis and/or E. canis, while B. burgdorferi (sensu lato) transmission is minimal in the country. Practitioners play a fundamental role in the detection and control of these diseases to protect dogs and humans.
\end{abstract}

Keywords: Dogs, Epidemiology, Canine Vector-Borne Diseases, In-Clinic ELISA Tests

\footnotetext{
* Correspondence: rebeca.movilla@uab.cat

${ }^{1}$ Hospital Clínic Veterinari, Universitat Autònoma de Barcelona, Carrer de

I'Hospital, 08193 Cerdanyola del Vallès, Barcelona, Spain

Full list of author information is available at the end of the article
} 


\section{Background}

In the last decades, worldwide emergence and reemergence of many canine vector-borne diseases (CVBD) have been documented [1-4]. A diverse range of pathogens transmitted by haematophagous arthropods, mainly ticks and mosquitoes, cause CVBD [5], which have become a major focus of interest due to their importance to canine and human public health. In addition to suffering from illness, dogs can be subclinically infected and act as reservoir hosts for arthropod-transmitted zoonotic pathogens [6]. The increasing canine population and the close relationship with humans in both rural and urban areas add new concerns [7].

Anaplasmosis, borreliosis, dirofilariosis and ehrlichiosis have been recognized as some of the major CVBD with global significance [8].

Anaplasma phagocytophilum is a Gram-negative obligate intracellular bacterium, transmitted by ticks of the genus Ixodes. Anaplasma phagocytophilum infects granulocytes, mainly neutrophils, causing granulocytic anaplasmosis in mammalian hosts, including dogs and humans [9]. Anaplasma platys, transmitted by $R$. sanguineus (sensu lato) infects canine platelets and is responsible for the infectious canine cyclic thrombocytopenia. Pathogenicity is generally low but $A$. platys may play a role in co-infection with other arthropod-borne diseases [10]. The close molecular relationship between $A$. phagocytophilum and A. platys limits the serological differentiation between both agents due to cross-reactions [11].
Borrelia burgdorferi (sensu lato) is the causative agent of Lyme disease or borreliosis in mammalian hosts. Ticks of the genus Ixodes are the main vectors of this spirochete [12]. Dogs are susceptible to infection but clinical disease generally is milder and less frequent than in humans [13]. Because of their frequent exposure to ticks and ready seroconversion, dogs have been proposed as sentinels for risk of Lyme disease in humans [14].

Cardiopulmonary dirofilariosis is a potentially fatal disease caused by infection mainly with the adult stages of the nematode Dirofilaria immitis, also known as heartworm, and mosquitoes of the genus Aedes and Culex are considered main vectors [15]. Human heartworm infection is incidental and typically not associated with severe clinical signs. However, human cases have been reported in areas of high canine prevalence, highlighting the importance of heartworm testing and chemoprophylaxis in dogs to reduce transmission [16].

The Gram-negative bacterium Ehrlichia canis is the causative agent of canine monocytic ehrlichiosis, transmitted worldwide by the brown dog tick Rhipicephalus sanguineus (sensu lato) $[17,18]$. Diagnosis is challenging due to its different phases and multiple clinical-pathological manifestations $[19,20]$.

Prevalence of CVBD is dependent on favourable climate and habitat for the microbiologic pathogens, their arthropod vectors and their mammalian reservoirs [2]. Mexico has a great diversity of climates determined by

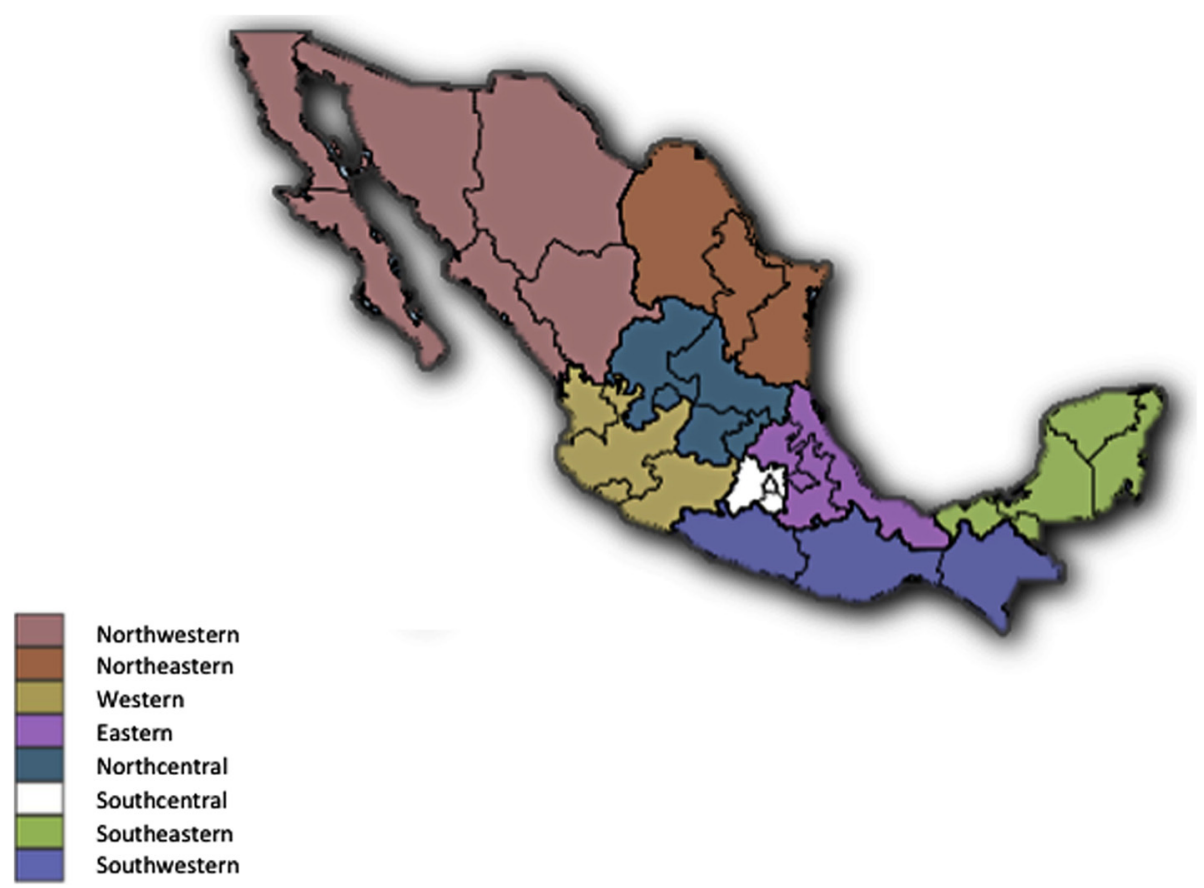

Fig. 1 Geoeconomic regions of Mexico. Distribution of the federated states of Mexico, according to a geoeconomic division, into eight different geoeconomic regions as follows: northwestern, northeastern, western, eastern, northcentral, southcentral,southeastern and southwestern 
several factors such as the altitude, geographical latitude, weather conditions and the existing distribution of land and water [21]. The existence of favourable environments for the development of CVBD across the country has already been demonstrated, but knowledge of the prevalence and distribution of CVBD in Mexico is scarce and most data rely on geographically limited studies and/or the assessment of a low number of pathogens [22-31].

Epidemiological tools are essential to guide the definitive etiological diagnosis of CVBD and establish adequate methods for prevention [32]. Studies mapping the national seroprevalence of certain CVBD agents have been recently conducted in other countries [33-49]. However, to the authors' knowledge, this is the first description in Mexico at the countrywide level.

This study aimed to add useful information about the national serological distribution and epidemiological associations of four important vector-borne pathogens among dogs from different Mexican states.

\section{Methods}

\section{Source of data}

Seventy-four veterinary centres located in 28 cities represented 21 out of 32 Federate Mexican states in this study. Cities were selected in locations where CVBD agents are more likely to be found. In order to geographically assess canine seroprevalence, states were grouped into eight different geoeconomic regions: northwestern (Baja California Norte, Baja California Sur, Chihuahua, Sinaloa and Sonora), northeastern (Coahuila and Nuevo Leon), western (Colima, Jalisco and Nayarit), eastern (Puebla, Veracruz and Hidalgo), northcentral (Aguascalientes, Guanajuato and Querétaro), southcentral (Morelos), southeastern (Quintana Roo and Yucatán) and southwestern (Chiapas and Guerrero) (Fig. 1).

Each veterinary centre received at least 30 in-clinic tests. Veterinarians were asked to test dogs with clinical signs suspect for anaplasmosis, borreliosis, dirofilariosis and/or ehrlichiosis, and a similar number of apparently healthy dogs, under physical examination, from April 2011 to January 2012. Inclusion criteria for testing sick dogs was considered for the presence of one or more of the following clinical alterations: lethargy, hyperthermia, weakness, weight loss, oedema, polyuria-polydipsia, lymph node enlargement, joint inflammation, lameness, cough, dyspnoea, nasal discharge, pale mucous membranes, haemorrhagic disorders, ocular lesions or neurologic signs. The absence of consistent history and/or evidence of abnormalities compatible with CVBD were considered exclusion criteria and these dogs were included in the healthy group.

The study was carried out in accordance with the International Guiding Principles for Biomedical Research
Involving Animals, issued by the Council for the International Organizations of Medical Sciences. Dogs were entered in the study under owner consent. Veterinarians recorded additional data of the dogs using a questionnaire

Table 1 Population description

\begin{tabular}{|c|c|c|c|c|}
\hline \multirow[t]{2}{*}{ Characteristic } & \multicolumn{3}{|c|}{ Health status } & \multirow{2}{*}{$\begin{array}{l}\text { Total } \\
\text { population }\end{array}$} \\
\hline & $\begin{array}{l}\text { Healthy } \\
\text { dogs }\end{array}$ & $\begin{array}{l}\text { CVBD-suspect } \\
\text { dogs }\end{array}$ & $\begin{array}{l}\text { Not } \\
\text { known }\end{array}$ & \\
\hline \multicolumn{5}{|l|}{ Gender } \\
\hline Male & 486 & 392 & 23 & 901 \\
\hline Female & 442 & 322 & 17 & 781 \\
\hline Not known & 15 & 8 & 1 & 24 \\
\hline \multicolumn{5}{|l|}{ Age } \\
\hline$<1$ year & 41 & 36 & 5 & 82 \\
\hline$\geq 1$ year & 874 & 667 & 29 & 1570 \\
\hline Not known & 28 & 19 & 7 & 54 \\
\hline \multirow[t]{2}{*}{ Median age } & 4 years & 5 years & 5 years & 5 years \\
\hline & IQR: 2-7 & IQR: 3-8 & IQR: 3-9 & IQR: 3-8 \\
\hline \multicolumn{5}{|l|}{ Size } \\
\hline $\begin{array}{l}\text { Small } \\
(<10 \mathrm{~kg})\end{array}$ & 383 & 234 & 14 & 631 \\
\hline $\begin{array}{l}\text { Medium } \\
(10-25 \mathrm{~kg})\end{array}$ & 103 & 121 & 2 & 226 \\
\hline $\begin{array}{l}\text { Large } \\
(>25 \mathrm{~kg})\end{array}$ & 304 & 200 & 18 & 522 \\
\hline Not known & 153 & 167 & 7 & 327 \\
\hline \multicolumn{5}{|l|}{ Lifestyle } \\
\hline Indoors & 269 & 166 & 12 & 447 \\
\hline Outdoors & 620 & 516 & 23 & 1159 \\
\hline Not known & 54 & 40 & 6 & 100 \\
\hline \multicolumn{5}{|l|}{ Tick contact } \\
\hline Yes & 627 & 602 & 29 & 1258 \\
\hline No & 268 & 68 & 5 & 341 \\
\hline Not known & 48 & 52 & 7 & 107 \\
\hline \multicolumn{5}{|l|}{ TTI prevention } \\
\hline Yes & 46 & 36 & 3 & 85 \\
\hline No & 890 & 676 & 27 & 1593 \\
\hline Not known & 7 & 10 & 11 & 28 \\
\hline \multicolumn{5}{|l|}{ MTI prevention } \\
\hline Yes & 43 & 42 & 0 & 85 \\
\hline No & 891 & 667 & 27 & 1585 \\
\hline Not known & 9 & 13 & 14 & 36 \\
\hline \multicolumn{5}{|l|}{ Travel history } \\
\hline Yes & 176 & 151 & 4 & 331 \\
\hline No & 763 & 569 & 33 & 1365 \\
\hline Not known & 4 & 2 & 4 & 10 \\
\hline
\end{tabular}

Abbreviations: IQR interquartile range, $T T I$ tick-transmitted infections, $M T$ mosquito-transmitted infections 
that included health status, gender, age $(<1$ year or $\geq$ 1 year), size [small $(<10 \mathrm{~kg})$, medium $(10-25 \mathrm{~kg})$ or large (> $25 \mathrm{~kg}$ )], lifestyle (outdoors or indoors), detectable tick infestation, use of treatment (mainly tetracycline, doxycycline, imidocarb and/or ivermectin) against tick and mosquito-transmitted infections as those evaluated here, and travel history to other regions or abroad.

\section{Serological testing}

Whole blood, serum or plasma samples from dogs were tested by means of a rapid in-clinic enzyme-linked immunosorbent assay (ELISA) kit (SNAP ${ }^{\oplus} 4 \mathrm{Dx}^{\bullet}$ from IDEXX $^{\oplus}$ Laboratories, Westbrook, Maine, USA), according to the instructions listed in the product package insert. This assay screens for simultaneous qualitative detection of a circulating carbohydrate of $D$. immitis antigen, from the adult female heartworms, and antibodies, immunoglobulin $\mathrm{G}$ and $\mathrm{M}$, against immunodominant proteins of $A$. phagocytophylum (p44/MSP2), $B$. burgdorferi (sensu lato) (C6) and E. canis (p30 and p301). Preliminary studies indicate that $A$. phagocytophilum analyte in $\mathrm{SNAP}^{\otimes} 4 \mathrm{Dx}^{\circledast}$ cross-reacts with samples from $A$. platys-infected dogs (SNAP ${ }^{\oplus} 4 \mathrm{Dx}^{\oplus}$ kit insert, unpublished data). Reported sensitivity and specificity of the inclinic ELISA for detection of antibodies are 99.1 and $100 \%$ for $A$. phagocytophilum, 98.8 and $100 \%$ for $B$. burgdorferi (sensu lato) and 96.2 and $100 \%$ for $E$. canis. Reported sensitivity and specificity for detection of heartworm antigen were 99.2 and $100 \%$, respectively [50].

\section{Data analysis}

Statistical analysis was performed using SPSS 20.0 software. Values for prevalence were established. Chi-square and Fisher's exact tests were used to compare proportions of positivity related to categorical dependent variables. A probability $P$-value $<0.05$ was considered statistically significant. Logistic regression analysis was subsequently performed. Significant differences between categories were quantified calculating odds ratios (OR) and their $95 \%$ confidence intervals (CI).

\section{Results}

Practitioners tested a total of 1706 dogs over the study period. Information about health status was recorded for 1665 dogs: 943 apparently healthy and 722 CVBDsuspect dogs; no data were available for 41 dogs. Table 1 summarizes the characteristics of the population.

Overall and regional seroprevalence of all the dogs included in the study, apparently healthy dogs and CVBDsuspect dogs are shown in Tables 2, 3 and 4 .

Table 2 Geographical distribution of seroprevalence to CVBD agents among all the dogs included in the study

\begin{tabular}{|c|c|c|c|c|c|c|c|}
\hline \multirow[t]{2}{*}{ Region } & \multirow[t]{2}{*}{ Dogs } & \multirow{2}{*}{$\begin{array}{l}\text { Dogs } \\
\text { infected (\%) } \\
{[95 \% \text { Cl] }}\end{array}$} & \multicolumn{4}{|c|}{ Positivity (\%) [95 \% Cl] } & \multirow{2}{*}{$\begin{array}{l}\text { Dogs } \\
\text { co-infected (\%) } \\
{[95 \% \mathrm{Cl}]}\end{array}$} \\
\hline & & & $A$ & $B b$ & $D i$ & Ec & \\
\hline \multirow[t]{2}{*}{ Northwestern } & \multirow[t]{2}{*}{384} & $213(55.47)^{* *}$ & $63(16.4)^{* *}$ & $1(0.26)$ & $25(6.51)$ & $196(51.04)^{* *}$ & $64(16.67)^{* *}$ \\
\hline & & {$[50.3-60.2]$} & [12.8-20.1] & {$[0.0-0.8]$} & {$[4.2-9.4]$} & [46.1-56.0] & [12.5-20.3] \\
\hline \multirow[t]{2}{*}{ Northeastern } & \multirow[t]{2}{*}{349} & $114(32.66)$ & $23(6.59)^{*}$ & $1(0.29)$ & $31(8.88)^{*}$ & $80(22.9)^{* *}$ & $19(5.44)^{*}$ \\
\hline & & {$[27.8-37.5]$} & {$[4.3-9.2]$} & {$[0.0-0.8]$} & {$[6.0-12.0]$} & [18.6-27.5] & {$[3.4-8.0]$} \\
\hline \multirow[t]{2}{*}{ Northcentral } & \multirow[t]{2}{*}{164} & $4(2.44)^{* *}$ & $1(0.61)^{* *}$ & $0(0)$ & $0(0)^{*}$ & $4(2.43)^{* *}$ & $1(0.61)^{* *}$ \\
\hline & & {$[0.6-4.9]$} & {$[0.0-1.8]$} & {$[0.0-0.0]$} & {$[0.0-0.0]$} & {$[0.6-4.9]$} & {$[0.0-1.8]$} \\
\hline \multirow[t]{2}{*}{ Western } & \multirow[t]{2}{*}{140} & $54(38.57)$ & $14(10)$ & $0(0)$ & $3(2.14)$ & $52(37.14)$ & $15(10.71)$ \\
\hline & & {$[30.5-46.4]$} & {$[5.7-15.0]$} & {$[0.0-0.0]$} & {$[0.0-5.0]$} & {$[28.6-45.0]$} & {$[5.7-15.7]$} \\
\hline \multirow[t]{2}{*}{ Eastern } & \multirow[t]{2}{*}{205} & $54(26.34)^{*}$ & $18(8.78)$ & $1(0.49)$ & $10(4.88)$ & $37(18.05)^{* *}$ & $11(5.37)$ \\
\hline & & {$[20.5-32.2]$} & {$[4.9-12.7]$} & {$[0.0-1.5]$} & {$[2.0-7.8]$} & [13.0-23.4] & {$[2.4-8.8]$} \\
\hline \multirow[t]{2}{*}{ Southcentral } & \multirow[t]{2}{*}{86} & $17(19.77)^{*}$ & $4(4.65)$ & $0(0)$ & $2(2.32)$ & $13(15.12)^{*}$ & $2(2.32)^{*}$ \\
\hline & & [11.6-29.1] & {$[1.2-9.3]$} & {$[0.0-0.0]$} & {$[0.0-5.8]$} & {$[8.1-23.3]$} & {$[0.0-5.8]$} \\
\hline \multirow[t]{2}{*}{ Southwestern } & \multirow[t]{2}{*}{149} & $67(44.97)^{*}$ & $19(12.75)$ & $0(0)$ & $2(1.34)^{*}$ & $63(42.3)^{*}$ & $16(10.74)$ \\
\hline & & [36.9-53.0] & [7.4-18.8] & {$[0.0-0.0]$} & {$[0.0-3.4]$} & [34.2-50.3] & [6.0-16.1] \\
\hline \multirow[t]{2}{*}{ Southeastern } & \multirow[t]{2}{*}{229} & $103(44.98)^{*}$ & 27 (11.79) & $1(0.44)$ & $18(7.86)$ & 81 (35.37) & $23(10.04)$ \\
\hline & & [38.4-51.5] & [7.4-16.2] & {$[0.0-1.3]$} & [4.8-11.8] & [29.3-41.5] & [6.6-14.0] \\
\hline \multirow{2}{*}{$\begin{array}{l}\text { Mexican } \\
\text { states }\end{array}$} & \multirow[t]{2}{*}{1706} & $626(36.7)$ & $169(9.91)$ & $4(0.23)$ & $91(5.33)$ & $526(30.83)$ & $151(8.85)$ \\
\hline & & [34.3-39.0] & [8.6-11.4] & {$[0.1-0.5]$} & {$[4.3-6.4]$} & [28.7-33.1] & {$[7.5-10.2]$} \\
\hline
\end{tabular}

Abbreviations: A Anaplasma spp., Bb Borrelia burgdorferi (sensu lato), Di Dirofilaria immitis, Ec Ehrlichia canis

* Statistically significant difference $(P<0.05)$; ${ }^{*}$ Statistically significant difference $(P<0.0001)$ to the corresponding national average value of prevalence 
Table 3 Geographical distribution of seroprevalence to CVBD agents among apparently healthy dogs

\begin{tabular}{|c|c|c|c|c|c|c|c|}
\hline \multicolumn{8}{|c|}{ Apparently healthy dogs } \\
\hline \multirow[t]{2}{*}{ Region } & \multirow[t]{2}{*}{ Dogs } & \multirow{2}{*}{$\begin{array}{l}\text { Dogs infected } \\
\text { (\%) }[95 \% \mathrm{Cl}]\end{array}$} & \multicolumn{4}{|c|}{ Positivity (\%) [95 \% Cl] } & \multirow{2}{*}{$\begin{array}{l}\text { Dogs co-infected } \\
\text { (\%) }[95 \% \mathrm{Cl}]\end{array}$} \\
\hline & & & $A$ & $B b$ & Di & EC & \\
\hline \multirow[t]{2}{*}{ Northwestern } & \multirow[t]{2}{*}{177} & $62(35.03)^{* *}$ & $22(12.43)^{* *}$ & $0(0)$ & $10(5.65)$ & $55(31.07)^{* *}$ & $21(11.86)^{* *}$ \\
\hline & & {$[28.2-41.8]$} & {$[7.9-17.5]$} & {$[0.0-0.0]$} & {$[2.8-9.0]$} & {$[24.7-37.9]$} & {$[7.3-16.9]$} \\
\hline \multirow[t]{2}{*}{ Northeastern } & \multirow[t]{2}{*}{223} & $48(21.52)$ & $6(2.69)^{*}$ & $0(0)$ & $13(5.83)^{*}$ & $33(14.79)$ & $4(1.79)$ \\
\hline & & [16.6-26.9] & {$[0.9-4.9]$} & {$[0.0-0.0]$} & {$[3.1-9.0]$} & {$[10.3-19.4]$} & {$[0.4-3.6]$} \\
\hline \multirow[t]{2}{*}{ Northcentral } & \multirow[t]{2}{*}{107} & $0(0)^{* *}$ & $0(0)^{*}$ & $0(0)$ & $0(0)^{*}$ & $0(0)^{* *}$ & $0(0)^{*}$ \\
\hline & & {$[0.0-0.0]$} & {$[0.0-0.0]$} & {$[0.0-0.0]$} & {$[0.0-0.0]$} & {$[0.0-0.0]$} & {$[0.0-0.0]$} \\
\hline \multirow[t]{2}{*}{ Western } & \multirow[t]{2}{*}{57} & $19(33.33)$ & $4(7.02)$ & $0(0)$ & $2(3.51)$ & $17(29.82)$ & $4(7.02)$ \\
\hline & & {$[21.1-45.6]$} & {$[1.8-14.0]$} & {$[0.0-0.0]$} & {$[0.0-8.8]$} & {$[17.5-42.1]$} & {$[1.8-14.0]$} \\
\hline \multirow[t]{2}{*}{ Eastern } & \multirow[t]{2}{*}{131} & $26(19.85)$ & $7(5.34)$ & $0(0)$ & $5(3.82)$ & $17(12.98)$ & $2(1.53)$ \\
\hline & & {$[13.0-27.5]$} & {$[1.5-9.2]$} & {$[0.0-0.0]$} & {$[0.8-7.6]$} & {$[7.6-19.1]$} & {$[0.0-3.8]$} \\
\hline \multirow[t]{2}{*}{ Southcentral } & \multirow[t]{2}{*}{46} & $5(10.87)^{*}$ & $2(4.35)$ & $0(0)$ & $0(0)$ & $4(8.69)$ & $1(2.17)$ \\
\hline & & [2.2-20.3] & [0.0-10.9] & {$[0.0-0.0]$} & {$[0.0-0.0]$} & {$[2.2-17.4]$} & {$[0.0-6.5]$} \\
\hline \multirow[t]{2}{*}{ Southwestern } & \multirow[t]{2}{*}{86} & $34(39.53)^{*}$ & $5(5.81)$ & $0(0)$ & $0(0)$ & $32(37.21)^{* *}$ & $3(3.49)$ \\
\hline & & [29.1-50.0] & [1.2-11.6] & {$[0.0-0.0]$} & {$[0.0-0.0]$} & {$[27.5-47.7]$} & {$[0.0-8.1]$} \\
\hline \multirow[t]{2}{*}{ South-eastern } & \multirow[t]{2}{*}{116} & $33(28.45)$ & $12(10.35)$ & $0(0)$ & $1(0.86)$ & $24(20.69)$ & $4(3.45)$ \\
\hline & & [20.7-37.1] & {$[5.2-16.4]$} & {$[0.0-0.0]$} & {$[0.0-2.6]$} & [13.8-28.4] & [0.9-6.9] \\
\hline \multirow{2}{*}{$\begin{array}{l}\text { Mexican } \\
\text { states }\end{array}$} & \multirow[t]{2}{*}{943} & $227(24.07)$ & $58(6.15)$ & $0(0)$ & $31(3.29)$ & $182(19.30)$ & $39(4.13)$ \\
\hline & & [21.3-26.8] & [4.7-7.6] & {$[0.0-0.0]$} & {$[2.2-4.5]$} & [16.8-21.8] & [3.0-5.5] \\
\hline
\end{tabular}

Abbreviations: A Anaplasma spp., Bb Borrelia burgdorferi (sensu lato), Di Dirofilaria immitis, Ec Ehrlichia canis

* Statistically significant difference $(P<0.05) ;{ }^{*}$ Statistically significant difference $(P<0.0001)$ to the corresponding national average value of prevalence

Of the 1706 dogs tested, 626 (36.7\%) were positive to one or more agents. The highest prevalence was detected in the Northwest (55.5\%), where seropositivity to E. canis (51.0 \%) and Anaplasma spp. (16.4 \%) was significantly higher than in the remaining regions. Dirofilaria immitis was more frequently detected in the Northeast (8.9 \%). However, seropositivity to B. burgdorferi (sensu lato) was similar in the eight regions. Lowest seroprevalence was observed in the northcentral area of the country $(2.4 \%)$.

Table 5 describes positive results for more than one agent in 151 of 1706 dogs (8.8\%), mostly between $E$. canis and Anaplasma spp. No dog was positive for all agents.

Seropositivity to the different CVBD agents according to the variables analysed is shown in Table 6. Odds ratios (OR) and $95 \% \mathrm{CI}$ for binomial variables presenting significant associations are summarized in Table 7. For all of the dogs examined no association was observed between gender and any CVBD agent. Overall, dogs aged 1 year-old or older presented a higher prevalence $(37.0 \%)$ than dogs aged less than 1 year $(23.2 \%), \chi^{2}=$ $6.450, d f=1, P<0.011$. Positivity among small-sized dogs (27.6\%) was significantly lower than positivity for medium (43.4 \%) and large breed dogs (39.8\%), $\chi^{2}=$ 27.676, $d f=2, P<0.001$. Prevalence among dogs living outdoors was higher than indoors (42.0 and $23.7 \%$, respectively; $\left.X^{2}=46.412, d f=1, P<0.001\right)$. Dogs with detectable tick contact were more frequently positive to CVBD agents $(43.3 \%)$ than dogs without ticks (9.7 \%), $\chi^{2}=131.577, d f=1, P<0.001$. In addition, higher prevalence was detected among dogs that received treatment for tick-transmitted infections than dogs that did not (58.8 and $35.6 \%$, respectively; $X^{2}=$ 18.730, $d f=1, P<0.001$ ), while receiving treatment for mosquito-transmitted infections was not linked to the presence of CVBD agents. No relationship was detected between positivity and previous travel history. Seropositivity was a risk factor for the presence of clinical signs $\left(\chi^{2}=\right.$ 149.200, $d f=1, P<0.001$ ).

\section{Discussion}

Countrywide serological evaluation for four CVBD agents was carried out in Mexico. The regions described in the study presented here resulted from a geoeconomic division of the country. This classification is not coincidental with a climatic division, which according to humidity and temperature categorizes the country into areas with a warm wet, warm humid, dry, very dry, mild humid and mild wet climate (Fig. 2) [21].

Seropositivity values for Anaplasma spp., B. burgdorferi (sensu lato), D. immitis and E. canis reported here 
Table 4 Geographical distribution of seroprevalence to CVBD agents among dogs with clinical signs

\begin{tabular}{|c|c|c|c|c|c|c|c|}
\hline \multicolumn{8}{|c|}{ CVBD-suspect dogs } \\
\hline \multirow[t]{2}{*}{ Region } & \multirow[t]{2}{*}{ Dogs } & \multirow{2}{*}{$\begin{array}{l}\text { Dogs infected } \\
\text { (\%) }[95 \% \mathrm{Cl}]\end{array}$} & \multicolumn{4}{|c|}{ Positivity (\%) [95% Cl] } & \multirow{2}{*}{$\begin{array}{l}\text { Dogs co-infected } \\
\text { (\%) }[95 \% \mathrm{Cl}]\end{array}$} \\
\hline & & & $\bar{A}$ & $B b$ & Di & EC & \\
\hline \multirow[t]{2}{*}{ Northwestern } & \multirow[t]{2}{*}{203} & $149(73.39)^{* *}$ & $41(20.19)^{*}$ & $1(0.49)$ & $14(6.89)$ & $140(68.96)^{* *}$ & $43(21.18)^{*}$ \\
\hline & & {$[66.5-78.8]$} & {$[14.8-25.6]$} & {$[0.0-01.5]$} & {$[0.0-0.0]$} & {$[62.6-74.9]$} & {$[14.8-26.3]$} \\
\hline \multirow[t]{2}{*}{ Northeastern } & \multirow[t]{2}{*}{113} & $59(52.21)$ & $14(12.39)$ & $1(0.88)$ & $16(14.16)^{*}$ & $43(38.05)$ & $13(11.50)$ \\
\hline & & {$[42.5-61.1]$} & {$[6.2-19.5]$} & {$[0.0-2.7]$} & {$[8.0-20.4]$} & {$[29.2-47.8]$} & {$[5.3-17.7]$} \\
\hline \multirow[t]{2}{*}{ Northcentral } & \multirow[t]{2}{*}{55} & $4(7.27)^{* *}$ & $1(1.81)^{*}$ & $0(0)$ & $0(0)^{*}$ & $4(7.27)^{* *}$ & $1(1.81)^{*}$ \\
\hline & & {$[1.8-14.5]$} & {$[0.0-5.5]$} & {$[0.0-0.0]$} & {$[0.0-0.0]$} & {$[1.8-14.5]$} & {$[0.0-5.5]$} \\
\hline \multirow[t]{2}{*}{ Western } & \multirow[t]{2}{*}{82} & $35(42.68)^{*}$ & $10(12.19)$ & $0(0)$ & $1(1.22)^{*}$ & $35(42.68)$ & $11(13.41)$ \\
\hline & & {$[32.9-53.7]$} & {$[6.1-19.5]$} & {$[0.0-0.0]$} & {$[0.0-3.7]$} & {$[31.7-52.4]$} & {$[6.1-20.7]$} \\
\hline \multirow[t]{2}{*}{ Eastern } & \multirow[t]{2}{*}{70} & $28(40.0)^{*}$ & $11(15.71)$ & $1(1.43)$ & $5(7.14)$ & $20(28.57)^{*}$ & $9(12.86)$ \\
\hline & & {$[28.6-51.4]$} & {$[7.1-24.3]$} & {$[0.0-4.3]$} & {$[1.4-12.9]$} & {$[18.6-40.0]$} & {$[5.7-21.4]$} \\
\hline \multirow[t]{2}{*}{ Southcentral } & \multirow[t]{2}{*}{39} & $12(30.77)^{*}$ & $2(5.13)$ & $0(0)$ & $2(5.13)$ & $9(23.08)^{*}$ & $1(2.56)^{*}$ \\
\hline & & [17.1-46.2] & {$[0.0-12.8]$} & {$[0.0-0.0]$} & {$[0.0-12.8]$} & [10.3-35.9] & {$[0.0-7.7]$} \\
\hline \multirow[t]{2}{*}{ Southwestern } & \multirow[t]{2}{*}{53} & $27(50.94)$ & $12(22.64)$ & $0(0)$ & $2(3.77)$ & $25(47.17)$ & $11(20.75)$ \\
\hline & & [37.7-64.2] & [11.3-35.8] & {$[0.0-0.0]$} & [0.0-9.4] & [34.0-60.4] & [11.3-32.1] \\
\hline \multirow[t]{2}{*}{ Southeastern } & \multirow[t]{2}{*}{107} & $70(65.42)^{*}$ & $15(14.01)$ & $1(0.93)$ & $17(15.89)^{*}$ & $57(53.27)$ & $19(17.76)$ \\
\hline & & [56.1-73.8] & [7.5-20.6] & {$[0.0-3.1]$} & [9.3-23.4] & [43.0-62.6] & [10.9-25.2] \\
\hline \multirow[t]{2}{*}{ Mexican states } & \multirow[t]{2}{*}{722} & $384(53.18)$ & $106(14.68)$ & $4(0.56)$ & $57(7.89)$ & $333(46.12)$ & $108(14.96)$ \\
\hline & & [49.5-56.9] & [12.3-17.3] & [0.1-1.1] & [6.0-10.0] & [42.4-49.7] & [12.3-17.6] \\
\hline
\end{tabular}

Abbreviations: A Anaplasma spp., Bb Borrelia burgdorferi (sensu lato), Di Dirofilaria immitis, Ec Ehrlichia canis

* Statistically significant difference $(P<0.05) ;{ }^{* *}$ Statistically significant difference $(P<0.0001)$ to the corresponding national average value of prevalence

must be interpreted as current infection with or previous exposure to the pathogens under assessment.

Positive dogs to Anaplasma spp. were $9.9 \%$, with the highest prevalence detected in the northwestern (16.4\%) and lowest in the northcentral states of the country (0.6\%). Due to serological cross-reactivity between $A$. phagocytophilum and A. platys, results presented here indicated exposure to Anaplasma spp., but unfortunately the lack of molecular assessment limited species-level identification. To our knowledge, this is the first study documenting seroprevalence of Anaplasma spp. in several states of Mexico. To date only anecdotal reports have documented the presence of Anaplasma spp. in this country [31, 51]. Seroprevalence detected in the northeastern region in this study was $6.6 \%$. This percentage is higher than detected previously by ELISA testing (3\%) among 391 dogs from Monterrey (Nuevo León) [51]. In contrast, the prevalence of infection for Anaplasma 16S rRNA obtained by molecular identification in a recent study conducted among 100 healthy dogs infested by ticks, in Coahuila and Durango, was $31 \%$ [31].

The very low B. burgdorferi (sensu lato) seroprevalence $(0.2 \%)$ is one of the more important findings in this study. Each of the four positive dogs was from the eastern, southeastern, northeastern and northwestern region, respectively. Data were not completely recorded for these dogs, so if they were strays or pets that had traveled to Lyme endemic regions, it would not be unexpected to get such a low seroprevalence with a test with excellent specificity [50]. Alternatively, these could be false positives. All of the dogs positive for B. burgdorferi (sensu lato) presented clinical signs compatible with CVBD, that finding is in agreement with the fact that the SNAP 4DX kit could be more sensitive to detect antibodies during active infection [26], which could not explain the low seroprevalence recorded here. Low prevalence $(0.9 \%)$ was previously reported among 338 dogs from Nuevo Leon, detected by PCR assay [29]. In contrast, higher seroprevalence for B. burgdorferi (16 \%) was detected by indirect immunofluorescence assay among 850 dogs from Monterrey, a city located in the Northeast of Mexico [23]. A previous study conducted in the same area reported the presence of a high proportion of ticks infected with B. burgdorferi (sensu stricto), supporting that the Northeast should be considered a zone where Lyme disease is endemic [25]. A survey conducted in Mexico City and northeastern regions detected a seroprevalence of 3.43 and $6.2 \%$, respectively, among 2346 canine serum samples that were analysed by ELISA and subsequently confirmed by Western Blot technique [52]. Higher prevalence (8.2\%), was also 
Table 5 Positivity to single agents and co-infections among all dogs included in the study, apparently healthy and CVBD-suspect dogs

\begin{tabular}{|c|c|c|c|c|c|c|}
\hline \multirow[t]{2}{*}{ Pathogens } & \multicolumn{2}{|c|}{ Healthy dogs } & \multicolumn{2}{|c|}{ CVBD-suspect dogs } & \multicolumn{2}{|c|}{ Total population } \\
\hline & $n$ & $\%$ & $n$ & $\%$ & $n$ & $\%$ \\
\hline Single agent & 188 & $19.9^{*}$ & 276 & $38.2^{*}$ & 475 & 27.84 \\
\hline$A$ & 27 & 2.9 & 22 & 3.0 & 50 & 2.93 \\
\hline$B b$ & 0 & 0 & 2 & 0.3 & 2 & 0.12 \\
\hline Di & 16 & 1.7 & 23 & 3.2 & 42 & 2.46 \\
\hline Ec & 145 & $15.4^{*}$ & 229 & $31.7^{*}$ & 381 & 22.33 \\
\hline Co-infections & 39 & $4.1^{*}$ & 108 & $15^{*}$ & 151 & 8.85 \\
\hline$E C+D i$ & 8 & $0.8^{*}$ & 23 & $3.2^{*}$ & 31 & 1.82 \\
\hline$E c+B b$ & 0 & 0 & 1 & 0.1 & 1 & 0.06 \\
\hline$E C+A$ & 24 & $2.5^{*}$ & 72 & $10^{*}$ & 100 & 5.86 \\
\hline$D i+B b$ & 0 & 0 & 0 & 0 & 0 & 0 \\
\hline$D i+A$ & 2 & 0.2 & 4 & 0.6 & 6 & 0.35 \\
\hline$B b+A$ & 0 & 0 & 0 & 0 & 0 & 0 \\
\hline$E c+D i+B b$ & 0 & 0 & 0 & 0 & 0 & 0 \\
\hline$E C+D i+A$ & 5 & 0.5 & 7 & 1.0 & 12 & 0.7 \\
\hline$E c+B b+A$ & 0 & 0 & 1 & 0.1 & 1 & 0.06 \\
\hline$D i+B b+A$ & 0 & 0 & 0 & 0 & 0 & 0 \\
\hline$E c+D i+B b+A$ & 0 & 0 & 0 & 0 & 0 & 0 \\
\hline
\end{tabular}

Abbreviations: A Anaplasma spp., Bb B. burgdorferi (sensu lato), Di D. immitis, Ec E. canis "Statistically significant difference $(P<0.05)$

detected by ELISA in 94 dogs from Mexicali (Baja California), where the known vectors of this disease were not found [26].

Although little is known about Lyme disease and its transmission cycle in this country, seroprevalence of antibodies to $B$. burgdorferi (sensu lato) in dogs could be related to human cases of Lyme disease in Mexico [23]. A previous study concluded that the highest potential for transmission was found in high-altitude and lowtemperature regions, where Ixodes species are known vectors [28].

Epidemiological data about dirofilariosis in Mexico is very variable and results from previous studies are difficult to compare due to differences in the efficacy of the diverse diagnostic techniques used, size and geographical origin of the population examined and study season $[22,27]$. The prevalence of heartworm infection at the national level was previously estimated to be around $7.5 \%$ from Knott and ELISA diagnosis, with highest prevalence (19.6\%) among dogs from coastal areas [24]. In this study, D. immitis was detected in $5.3 \%$ of all dogs with the higher percentage of infection (8.9\%) in the notheastern region. Dirofilaria immitis was not detected in dogs from the northcentral area, which is in agreement with a previous publication that reported a low proportion of infection (1.3\%) in post-mortem examination of 378 dogs from Queretaro, Central Mexico [27]. Positivity of $7.9 \%$ for D. immitis was found in the southeastern region in the present study, which is comparable with previous reported data (8.3\%) in a study conducted in Yucatan among 676 dogs that were evaluated by modified Knott's and thick drop techniques in blood [53]. However, a study conducted in Celestun, a coastal locality in Southeast Mexico, detected a prevalence of infection as high as $59.8 \%$ among 279 asymptomatic dogs, probably because molecular techniques were used, the widespread distribution of mosquitoes and the presence of other mammals that might contribute to the infection of vectors [54]. The abundance of Ochlerotatus taeniorhynchus, a potential main vector in the coastal area, could be the most likely explanation for the difference in dirofilariasis prevalence observed between inland and coastal canine populations [54]. Moreover, a high percentage of co-infection with Trypanosoma cruzi, which may interfere significantly with host responses, has been reported in this region, encouraging prophylaxis for dogs $[55,56]$.

The overall $E$. canis seroprevalence documented here $(30.8 \%)$ is in accordance with the results of a previous survey conducted in 25 states of Mexico (33.1\%), which analysed 2395 canine blood samples by ELISA testing [57]. Ehrlichia canis accounts in this study for the highest prevalence $(51.0 \%)$ in the northwestern region, which is lower than reported before in the State of Sinaloa $(74.5 \%)$, although only 152 dogs infested with ticks were evaluated by ELISA testing in that study [58]. The high proportion of infection detected in the southeastern region $(35.4 \%)$ is in agreement with previous studies conducted in Yucatan $[30,59]$. Reported prevalence among 50 dogs by blood smear evaluation was $4 \%$, while $36 \%$ of these dogs were positive by PCR testing [30]. In the same study, higher values were found by molecular techniques when only dogs from an animal shelter were evaluated (45\%). It was presumed that those dogs were more likely infested by $R$. sanguineus (s.l.) and lived at a lower hygiene level [30]. Another survey conducted in the same area reported similar results among 120 dogs [59]. Analysis of blood samples using ELISA testing and blood smear evaluation showed 5.0 and $44.1 \%$ positivity, respectively [59]. However, results are in contrast to a previous survey performed in Yuca$\tan [60]$. That study included 309 stray dogs, which were evaluated by immunofluorescence antibody test in blood and indirect immunoperoxidase technique, reporting 8.7 and $8.1 \%$ prevalence of infection, respectively [60]. A possible explanation could be the diagnostic techniques used that differed greatly from ELISA testing performed in the present study. Seroprevalence in the northeastern region was $22.9 \%$. A lower prevalence for E. canis (4\%) has been previously detected by PCR among 100 healthy 
Table 6 Seropositivity for CVBD agents according to the epidemiological variables analysed

\begin{tabular}{|c|c|c|c|c|c|c|}
\hline \multirow{2}{*}{$\begin{array}{l}\text { Epidemiological } \\
\text { variable }(n)\end{array}$} & \multicolumn{6}{|c|}{ Total population seropositivity (\%) } \\
\hline & Dogs infected (\%) & $A$ & $B b$ & Di & EC & Dogs co-infected (\%, \\
\hline Gender & $P=0.205$ & $P=0.871$ & $P=0.886$ & $P=0.772$ & $P=0.291$ & $P=0.565$ \\
\hline Male (901) & $343(38.07)$ & 89 (9.88) & $2(0.22)$ & $49(5.44)$ & $288(31.96)$ & $77(8.55)$ \\
\hline Female (781) & $274(35.08)$ & $79(10.11)$ & $2(0.26)$ & $40(5.12)$ & $231(29.58)$ & $73(9.35)$ \\
\hline Age & $P=0.011$ & $P=0.958$ & $P=0.647$ & $P=0.096$ & $P=0.014$ & $P=0.379$ \\
\hline$<1$ year $(82)$ & $19(23.17)$ & $8(9.76)$ & $0(0)$ & $1(1.22)$ & $15(18.29)$ & $5(6.09)$ \\
\hline$\geq 1$ year $(1570)$ & $581(37.01)$ & $156(9.94)$ & $4(0.25)$ & $85(5.41)$ & $489(31.14)$ & $140(8.92)$ \\
\hline Size & $P<0.0001$ & $P=0.606$ & $P=0.542$ & $P=0.001$ & $P=0.047$ & $P<0.0001$ \\
\hline Small (631) & $174(27.58)$ & $44(6.97)$ & $0(0)$ & $13(2.06)$ & $146(23.14)$ & $27(4.28)$ \\
\hline Medium (226) & 98 (43.36) & $25(11.06)$ & $1(0.44)$ & $17(7.52)$ & 80 (35.39) & $23(10.18)$ \\
\hline Large (522) & 208 (39.85) & $55(10.54)$ & $2(0.38)$ & $36(6.89)$ & 172 (32.95) & $51(9.77)$ \\
\hline Lifestyle & $P<0.0001$ & $P=0.001$ & $P=0.214$ & $P<0.0001$ & $P<0.0001$ & $P<0.0001$ \\
\hline Indoors (447) & $106(23.71)$ & $27(6.04)$ & $0(0)$ & $8(1.79)$ & 88 (19.69) & $17(3.80)$ \\
\hline Outdoors (1159) & 487 (42.02) & $133(11.47)$ & $4(0.34)$ & 81 (6.99) & 407 (35.12) & 125 (10.78) \\
\hline Tick contact & $P<0.0001$ & $P<0.0001$ & $P=0.297$ & $P=0.002$ & $P<0.0001$ & $P<0.0001$ \\
\hline Yes (1258) & 545 (43.32) & $156(12.40)$ & $4(0.32)$ & 80 (6.36) & $458(36.40)$ & $141(11.21)$ \\
\hline No (341) & 33 (9.68) & $4(1.17)$ & $0(0.00)$ & $7(2.05)$ & $25(7.33)$ & $3(0.88)$ \\
\hline TTI prevention & $P<0.0001$ & $P=0.188$ & $P=0.069$ & $P=0.429$ & $P<0.0001$ & $P=0.033$ \\
\hline Yes (85) & $50(58.82)$ & $12(14.12)$ & $1(1.18)$ & $3(3.53)$ & $49(57.65)$ & $13(15.29)$ \\
\hline No (1593) & 567 (35.59) & 155 (9.73) & $3(0.19)$ & 88 (5.52) & $468(29.38)$ & $136(8.54)$ \\
\hline MTI prevention & $P=0.180$ & $P=0.354$ & $P=0.070$ & $P=0.484$ & $P=0.243$ & $P=0.085$ \\
\hline Yes (85) & 37 (43.53) & 11 (12.94) & $1(1.18)$ & $6(7.06)$ & $31(36.47)$ & $12(14.12)$ \\
\hline No (1585) & 576 (36.34) & $156(9.84)$ & $3(0.19)$ & $84(5.29)$ & $483(30.47)$ & $137(8.64)$ \\
\hline Clinical signs & $P<0.0001$ & $P<0.0001$ & $P=0.022$ & $P<0.0001$ & $P<0.0001$ & $P<0.0001$ \\
\hline Yes (722) & 384 (53.18) & 106 (14.68) & $4(0.55)$ & $57(7.89)$ & $333(46.12)$ & $108(14.96)$ \\
\hline No (943) & $227(24.07)$ & $58(6.15)$ & $0(0)$ & 31 (3.29) & $182(19.3)$ & $39(4.13)$ \\
\hline Travel history & $P=0.631$ & $P=0.680$ & $P=0.124$ & $P=0.453$ & $P=0.572$ & $P=0.742$ \\
\hline Yes (331) & 118 (35.65) & $35(10.57)$ & $2(0.60)$ & $15(4.53)$ & $98(29.61)$ & $31(9.36)$ \\
\hline No (1365) & $506(37.07)$ & $134(9.82)$ & $2(0.15)$ & $76(5.57)$ & $426(31.21)$ & $120(8.79)$ \\
\hline
\end{tabular}

Abbreviations: A Anaplasma spp., Bb B. burgdorferi (sensu lato), Di D. immitis, Ec E. canis, TTI tick-transmitted infections; MTI mosquito-transmitted infections

dogs infected with ticks, in Coahuila and Durango [31]. This disagreement may be due to the phenomenon black freezing that occurred during the sampling period of that study, which was characterized by an abnormally low average temperature of $-5{ }^{\circ} \mathrm{C}$, during four days in February, which decreased the amount of ticks infesting dogs. Another factor could be the different diagnostic techniques used. Additionally, all the dogs included in that study were healthy dogs, which is in contrast with the population included in the present survey [31].

Several epidemiological variables were considered in the present study, in order to evaluate potential associations with seropositivity to CVBD agents. Prevalence encountered for each pathogen varied depending on the geographical region. Despite this finding, dogs with travel history to other regions or abroad did not show significant differences in seroprevalence.

No link was detected between gender and positivity for CVBD agents, which is in agreement with previous studies [38, 43, 46, 59], even though distribution of tick infestation has been reported to be strongly dependent on female dogs because they are more sedentary than males when feeding their puppies [29].

Seropositivity value for $E$. canis in dogs aged one year or older was significantly higher compared with younger dogs. It is coincidental with previous studies that proposed the immunological status of the host or the increasing exposure to the vector with age as possible explanations for this finding $[39,59]$. Controversially, a survey performed in Spain showed a higher proportion 
Table 7 Risk factors for positivity to CVBD agents

\begin{tabular}{|c|c|c|c|}
\hline Dependent variable risk factor & $P$ & OR & $95 \% \mathrm{Cl}$ \\
\hline \multicolumn{4}{|l|}{ Positivity } \\
\hline$\geq 1$ year & 0.011 & 1.94 & $1.15-3.29$ \\
\hline Medium size & 0.003 & 1.54 & $1.16-2.07$ \\
\hline Large size & 0.002 & 1.42 & $1.14-1.79$ \\
\hline Outdoors & $<0.0001$ & 2.33 & $1.82-2.98$ \\
\hline Tick contact & $<0.0001$ & 7.13 & 4.89-10.39 \\
\hline TTI prevention & $<0.0001$ & 2.58 & $1.66-4.03$ \\
\hline Clinical signs & $<0.0001$ & 3.58 & $2.91-4.42$ \\
\hline \multicolumn{4}{|l|}{ Positivity to $A$} \\
\hline Outdoors & 0.001 & 2.02 & $1.31-3.09$ \\
\hline Tick contact & $<0.0001$ & 11.93 & $4.39-32.42$ \\
\hline Clinical signs & $<0.0001$ & 2.63 & $1.88-3.67$ \\
\hline \multicolumn{4}{|l|}{ Positivity to $B b$} \\
\hline Clinical signs & 0.022 & nd & nd \\
\hline \multicolumn{4}{|l|}{ Positivity to $\mathrm{Di}$} \\
\hline Medium size & 0.035 & 1.83 & $1.03-3.24$ \\
\hline Large size & 0.004 & 2.04 & $1.24-3.36$ \\
\hline Outdoors & $<0.0001$ & 4.12 & $1.98-8.59$ \\
\hline Tick contact & 0.002 & 3.24 & $1.48-7.08$ \\
\hline Clinical signs & $<0.0001$ & 2.52 & $1.61-3.95$ \\
\hline \multicolumn{4}{|l|}{ Positivity to $E C$} \\
\hline$\geq 1$ year & 0.014 & 2.02 & $1.14-3.57$ \\
\hline Medium size & 0.018 & 1.44 & $1.06-1.94$ \\
\hline Large size & 0.009 & 1.37 & $1.08-1.74$ \\
\hline Outdoors & $<0.0001$ & 2.21 & $1.69-2.87$ \\
\hline Tick contact & $<0.0001$ & 7.23 & $4.74-11.04$ \\
\hline Tा। prevention & $<0.0001$ & 3.27 & $2.10-5.09$ \\
\hline Clinical signs & $<0.0001$ & 3.58 & $2.88-4.45$ \\
\hline \multicolumn{4}{|l|}{ Co-infections } \\
\hline Large size & 0.007 & 1.75 & $1.16-2.62$ \\
\hline Outdoors & $<0.0001$ & 3.06 & $1.82-5.14$ \\
\hline Tick contact & $<0.0001$ & 14.22 & $4.50-44.91$ \\
\hline TTI prevention & 0.033 & 1.93 & $1.04-3.58$ \\
\hline Clinical signs & $<0.0001$ & 4.08 & $2.79-5.96$ \\
\hline
\end{tabular}

Abbreviations: $O R$ odds ratio, $\mathrm{Cl}$ confidence interval, $n d$ no data

of infection for E. canis and B. burgdorferi (sensu lato) among dogs aged less than one year compared to older dogs [43]. Comparable to other studies [22, 46], no significant association between age and positivity for the rest of the CVBD agents was detected in this study. By contrast, it has been suggested that the age of dogs could be an important risk factor for filarial infection, because older dogs are exposed for longer time periods to mosquito bites than younger dogs, in endemic areas $[39,56]$.

As reported previously [22], positivity among smallbreed dogs in this study was significantly lower compared to dogs of medium and large size.

Correlation between the presence of clinical signs and seropositivity was statistically significant for all of the CVBD agents analysed. Co-infections were the main cause of illness detected in CVBD-suspect dogs. According with previous publications, the most common combinations included Anaplasma spp., D. immitis and E. canis [39]. A previous report documenting high prevalence of $E$. canis infection in Mexico highlighted that almost half of the population remains subclinically infected [57]. Thus, a routine serological evaluation every six months was recommended in dogs presenting or not clinical signs consistent with CVBD [57]. In contrast, no relationship between seropositivity and the sick status of the dogs was found in studies conducted in other countries [35, 46]. It has been reported that clinical signs may vary among and within geographical locations. Proposed reasons include pathogen strain variations, dose of infectious organism, breed of dogs examined, immunological status of the host and concurrent infections with other CVBD agents [59].

As described before [30, 57], results showed that dogs infested with ticks had a higher percentage of seropositivity for all the pathogens under assessment. This conclusion would support the hypothesis that prevalence in dogs living outdoors should be higher compared to indoors, because the increased exposure to the vectors, but no significant association was detected between $B$. burgdorferi (sensu lato) infection and the place where dogs lived in this study. However, the low number of positive dogs for borreliosis detected in the study presented here precludes any conclusion.

Effective preventive measures are not always affordable in Mexico, so off-label injectable bovine ivermectin formulation and/or tetracycline, doxycycline and imidocarb are routinely used to treat suspected infections with CVBD agents [24]. The use of ivermectin promotes a reduction in the number of microfilaremic dogs and, therefore, the source of infection for the mosquito population. In addition, tetracyclines are known to destroy intracellular bacteria of the genus Wolbachia, a filarial endosymbiont, potentially contributing to a decline heartworm prevalence [24]. In contrast, dogs that received treatment for tick-transmitted infections, such as tetracycline, doxycycline or imidocarb, showed significantly higher seroprevalence for E. canis, in this study. Similar association was observed previously in an epidemiological study conducted in Romania [40]. One possible explanation for this finding is that most of the dogs treated for tick-transmitted infections in the study 


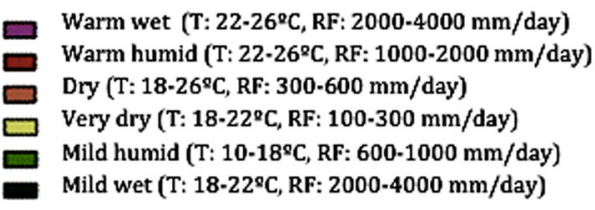

Fig. 2 Climatic regions of Mexico. Division of Mexico, according to humidity and temperature, into six different climatic areas with a warm wet, warm humid, dry, very dry, mild humid and mild wet climate, respectively

presented here had detectable infestation with ticks (76/85), one of the main risk factors for positivity to CVBD agents. On the other hand, positivity for any CVBD agent was not associated with the use of macrocyclic lactones against canine heartworm infection in the present survey.

One of the limitations of this study is that a geoeconomic division of the country instead of a climatic division was used when it was designed. Discrepancies between both classifications could have influenced the results obtained for different regions depending on the location of the veterinary practices. Furthermore, it is worthy of note that despite the wide geographical distribution of the veterinary centers that participated in this study, a potential bias derived from selection of the cities could have influenced the results obtained here.

\section{Conclusions}

This study adds valuable epidemiological information about the current situation of Anaplasma spp., $B$. burgdorferi (sensu lato), D. immitis and E. canis across Mexico. The findings highlight that dogs in Mexico are at risk of acquiring any of the zoonotic CVBD, which were under assessment. Veterinarians must be alert about this situation as they have a key role in the identification and control of these diseases in dogs and humans. Nowadays, updated information and products are widely available, which allows provision of better and more effective diagnostic and preventive programmes for dogs.

\section{Additional file}

Additional file 1: Dataset supporting the conclusions of this article. (XLSX $227 \mathrm{~kb})$

\section{Abbreviations}

A, Anaplasma spp.; Bb, Borrelia burgdorferi (sensu lato); Cl, confidence interval; CVBD, canine vector-borne disease; Di, Dirofilaria immitis; EC, Ehrlichia canis; ELISA, enzyme-linked immunosorbent assay; MTI, mosquito-transmitted infections; nd, no data; OR, odds ratio; $T$ Tl, tick-transmitted infections

\section{Acknowledgements}

This paper has been sponsored by Bayer Animal Health in the framework of the 11th CVBD World Forum Symposium. Authors are indebted to the veterinarians participating in this study and to Dr. Rafael Molina for the review of the statistical analysis.

\section{Funding}

The design of the study presented here, collection and analysis of samples became possible thanks to Bayer Animal Health in the framework of the 11th CVBD World Forum Symposium.

\section{Availability of data and materials}

The dataset supporting the conclusions of this article is included within the article and (Additional file 1).

\section{Authors' contributions}

SS, CG and XR designed the survey. RM performed the statistical analysis and interpretation of data and constructed the tables. CG designed the figures. RM drafted the first version. XR reviewed the first version. RM and XR finalized the manuscript. XR gave a final approval of the version to be published. All authors read and approved the final version of the manuscript.

Competing interests

The authors declare that they have no competing interests.

Consent for publication

Not applicable. 


\section{Ethics approval and consent to participate}

Blood samples collected in this study were taken as part of the diagnostic protocol for each dog, always under owner's consent, but not for research purposes. So, although an ethical committee was not applicable, it is worthy of note that the study was carried out in accordance with the International Guiding Principles for Biomedical Research Involving Animals, issued by the Council for the International Organizations of Medical Sciences.

\section{Author details}

'Hospital Clínic Veterinari, Universitat Autònoma de Barcelona, Carrer de I'Hospital, 08193 Cerdanyola del Vallès, Barcelona, Spain. ${ }^{2}$ Facultad de Medicina Veterinaria y Zootecnia, Facultad de Estudios Superiores Cuatitlán UNAM, Mexico Ciudad Universitaria, 04510 Mexico City D.F., Mexico. ${ }^{3}$ Bayer Animal Health GmbH, 40789 Monheim and Marketing Companion Animal Products (CAP), InternationalBuilding 6210, 2.56, 51368 Leverkusen, Germany.

Received: 21 February 2016 Accepted: 7 July 2016

Published online: 29 July 2016

\section{References}

1. Harrus S, Baneth G. Drivers for the emergence and re-emergence of vector-borne protozoal and bacterial diseases. Int J Parasitol. 2005;35:1309-18.

2. Fritz CL. Emerging tick-borne diseases. Vet Clin North Am Small Anim Pract. 2009;39:265-78.

3. Nicholson WL, Allen KE, McQuiston JH, Breitschwerdt EB, Little SE. The increasing recongnition of rickettsial pathogens in dogs and people. Trends Parasitol. 2010;26:205-12

4. Colwell DD, Dantas-Torres F, Otranto D. Vector-borne parasitic zoonoses: emerging scenarios and new perspectives. Vet Parasitol. 2011;182:14-21.

5. Beugnet F, Marie JL. Emerging arthropod-borne diseases of companion animals in Europe. Vet Parasitol. 2009;163:298-305.

6. Shaw SE, Day MJ, Birtles RJ, Breitschwerdt EB. Tick-borne infectious diseases of dogs. Trends Parasitol. 2001;17:74-80

7. Otranto D, Dantas-Torres F, Breitschwerdt EB. Managing canine vector-borne diseases of zoonotic concern: part one. Trends Parasitol. 2009;25:157-63.

8. Day MJ. The immunopathology of canine vector-borne diseases. Parasit Vectors. 2011:4:48.

9. Carrade DD, Foley JE, Borjesson DL, Sykes JE. Canine granulocytic anaplasmosis: a review. J Vet Intern Med. 2009;23:1129-41.

10. Little SE. Ehrlichiosis and anaplasmosis in dogs and cats. Vet Clin Small Anim. 2010:40:1121-40.

11. Dumler JS, Barbet AF, Bekker CP, Dasch GA, Palmer GH, Ray SC, et al. Reorganization of genera in the families Rickettsiaceae and Anaplasmataceae in the order Rickettsiales: unification of some species of Ehrlichia with Anaplasma, Cowdria with Ehrlichia with Neorickettsia, descriptions of six new species combination and designation of Ehrlichia equi and 'HGE agent' as subjective synonyms of Ehrlichia phagocytophila. Int J Syst Evol Microbiol. 2001;51:2145-65.

12. Littman MP, Goldstein RE, Labato MA, Lappin MR, Moore GE. ACVIM small animal consensus statement on Lyme disease in dogs: diagnosis, treatment and prevention. J Vet Intern Med. 2006;20:422-34.

13. Callister SM, Jobe DA, Schell RF, Lovrich SD, Onheiber KL, Korshus JB. Detection of borreliacidal antibodies in dogs after challenge with Borrelia burgdorferi-infected Ixodes scapularis ticks. J Clin Microbiol. 2000; 38:3670-74.

14. Duncan AW, Correa MT, Levine JF, Breitschwerdt EB. The dog as a sentinel for human infection: prevalence of Borrelia burgdorferi C6 antibodies in dogs from Southeastern and mid-Atlantic states. Vector Borne Zoonotic Dis. 2005; 5:101-9.

15. McCall JW, Genchi C, Kramer LH, Guerrero J, Venco L. Heartworm disease in animals and humans. Adv Parasitol. 2008;66:193-285.

16. Lee ACY, Montgomery SP, Theis JH, Blagburn BL, Eberhard ML. Public health issues concerning the widespread distribution of canine heartworm disease. Trends Parasitol. 2010;26:168-73.

17. Stich RW, Schaefer JJ, Bremer WG, Needham GR, Jittapalapong S. Host surveys, ixodid tick biology and transmission scenarios as related to the tick-borne pathogen, Ehrlichia canis. Vet Parasitol. 2008;158:256-73.

18. Dantas-Torres F, Latrofa MS, Annoscia G, Giannelli A, Parisi A, Otranto D. Morphological and genetic diversity of Rhipicephalus sanguineus sensu lato from the New and Old Worlds. Parasit Vectors. 2013;6:213.
19. Neer TM, Breitschwerdt EB, Greene RT, Lappin MR. Consensus statement on ehrlichial disease of small animals from the infectious disease study group of the ACVIM. American College of Veterinary Internal Medicine. J Vet Intern Med. 2002;16:309-15.

20. Harrus S, Wagner T. Diagnosis of canine monocytic ehrlichiosis (Ehrlichia canis): an overview. Vet J. 2011:187:292-6.

21. Clima en México, (CONAGUA) Comisión Nacional del Agua, Servicio Meteorológico Nacional, 2015. http://smn.cna.gob.mx. Accessed 2 Dec 2015.

22. Samano RF, Nájera R, Herrera D, Quiroz H. Frecuencia de Dirofilaria immitis en perros de seis ciudades de México. Vet Mex. 1996;27:107-9.

23. Salinas-Meléndez JA, Ávalos-Ramírez R, Riojas-Valdez VM, Martínez-Muñoz A. Serological survey of canine borreliosis. Rev Latin Microb. 1999;41:1-3.

24. Labarthe N, Guerrero J. Epidemiology of heartworm: what is happening in South America and Mexico? Vet Parasitol. 2005;133:149-56.

25. Gordillo-Pérez G, Vargas M, Solórzano-Santos F, Rivera A, Polaco OJ, Alvarado $L$, et al. Demonstration of Borrelia burgdorferi sensu stricto infection in ticks from the northeast of Mexico. Clin Microbiol Infect. 2009;15:496-8.

26. Tinoco-Gracia L, Quiroz-Romero H, Quintero-Martinez MT, Renteria-Evangelista TB, Barreras-Serrano A, Lopez-Valencia G, et al. Seroprevalence of Borrelia burgdorferi in dogs from a Mexico-U.S. border desert region: pilot study. J Anim Vet Adv. 2007:6:787-9.

27. Cantó GJ, García MP, García A, Guerrero MJ, Mosqueda J. The prevalence and abundance of helminth parasites in stray dogs form the city of Queretaro in central Mexico. J Helminthol. 2011;85:263-9.

28. Illoldi-Rangel P, Rivaldi CL, Sissel B, Trout R, Gordillo-Pérez G, RodríguezMoreno A, et al. Species distribution models and ecological suitability analysis for potential tick vectors of Lyme disease in Mexico. J Trop Med. 2012;2012:959101.

29. Galaviz-Silva L, Pérez-Treviño KC, Molina-Garza Z. Distribution of ixodid ticks on dogs in Nuevo León, Mexico, and their association with Borrelia burgdorferi sensu lato. Exp Appl Acarol. 2013;61:491-501.

30. Pat-Nah H, Rodríguez-Vivas Rl, Bolio-Gonzalez ME, Villegas-Pérez SL, Reyes-Novelo E. Molecular diagnosis of Ehrlichia canis in dogs and ticks Rhipicephalus sanguineus (Acari: Ixodidae) in Yucatan, Mexico. J Med Entomol. 2015;52:101-4.

31. Almazán C, González-Álvarez VH, de Mera FIG, Cabezas-Cruz A, Rodríguez-Martínez R, De la Fuente J. Molecular identification and characterization of Anaplasma platys and Ehrlichia canis in dogs in Mexico. Ticks Tick Borne Dis. 2016;7:276-83.

32. Otranto D, Dantas-Torres F, Breitschwerdt EB. Managing canine vector-borne diseases of zoonotic concern: part two. Trends Parasitol. 2009;25:228-35.

33. Pantchev N, Schaper R, Limousin S, Norden N, Weise M, Lorentzen L. Occurrence of Dirofilaria immitis and tick-borne infections caused by Anaplasma phagocytophilum, Borrelia burgdorferi sensu lato and Ehrlichia canis in domestic dogs in France: results of a countrywide serologic survey. Parasitol Res. 2009:105:101-13.

34. Bowmana D, Little SE, Lorentzen L, Shields J, Sullivan MP, Carlin EP. Prevalence and geographic distribution of Dirofilaria immitis, Borrelia burgdorferi, Ehrlichia canis, and Anaplasma phagocytophilum in dogs in the United States: results of a national clinic-based serologic survey. Vet Parasitol. 2009;160:138-48.

35. Couto G, Lorentzen L, Beall MJ, Shields J, Bertolone N, Couto Jl, et al. Serological study of selected vector-borne diseases in shelter dogs in central Spain using point-of-care assays. Vector Borne Zoonotic Dis. 2010;10:885-8.

36. Carrade D, Foley J, Sullivan M, Foley CW, Sykes JE. Spatial distribution of seroprevalence for Anaplasma phagocytophilum, Borrelia burgdorferi, Ehrlichia canis, and Dirofilaria immitis in dogs in Washington, Oregon, and California. Vet Clin Pathol. 2011;40:293-302.

37. Wong SS, Teng JL, Poon RW, Choi GK, Chan KH, Yeung ML, et al. Comparative evaluation of a point-of-care immunochromatographic test SNAP 4Dx with molecular detection tests for vector-borne canine pathogens in Hong Kong. Vector Borne Zoonotic Dis. 2011:11:1269-77.

38. Villeneuve A, Goring J, Marcotte L, Overvelde S. Seroprevalence of Borrelia burgdorferi, Anaplasma phagocytophilum, Ehrlichia canis, and Dirofilaria immitis among dogs in Canada. Can Vet J. 2011:52:527-30.

39. Cardoso L, Mendão C, de Carvalho ML. Prevalence of Dirofilaria immitis, Ehrlichia canis, Borrelia burgdorferi sensu lato, Anaplasma spp. and Leishmania infantum in apparently healthy and CVBD-suspect dogs in Portugal - a national serological study. Parasit Vectors. 2012;5:62. 
40. Mircean V, Dumitrache MO, Györke A, Pantchev N, Jodies R, Mihalca AD, Cozma V. Seroprevalence and geographic distribution of Dirofilaria immitis and tick-borne Infections (Anaplasma phagocytophilum, Borrelia burgdorferi sensu lato, and Ehrlichia canis) in dogs from Romania. Vector Borne Zoonotic Dis. 2012;12:595-604.

41. Xia Z, Yu D, Mao J, Zhang Z, Yu J. The occurrence of Dirofilaria immitis, Borrelia burgdorferi, Ehrlichia canis and Anaplasma phagocytophilum in dogs in China. J Helminthol. 2012;86:185-9.

42. Volgina NS, Romashov BV, Romashova NB, Shtannikov AV. Prevalence of borreliosis, anaplasmosis, ehrlichiosis and Dirofilaria immitis in dogs and vectors in Voronezh Reserve (Russia). Comp Immunol Microbiol Infect Dis. 2013;36:567-74.

43. Miró G, Montoya A, Roura X, Gálvez R, Sainz A. Seropositivity rates for agents of canine vector-borne diseases in Spain: a multicentre study. Parasit Vectors. 2013;6:117.

44. Krämer F, Schaper R, Schunack B, Połozowski A, Piekarska J, Szwedko A, et al. Serological detection of Anaplasma phagocytophilum, Borrelia burgdorferi sensu lato and Ehrlichia canis antibodies and Dirofilaria immitis antigen in a countrywide survey in dogs in Poland. Parasitol Res. 2014;113:3229-39.

45. McCown ME, Monterroso VH, Cardona W. Surveillance for Ehrlichia canis, Anaplasma phagocytophilum, Borrelia burgdorferi, and Dirofilaria immitis in dogs from three cities in Colombia. J Spec Oper Med. 2014;14:86-90.

46. Pérez Vera C, Kapiainen S, Junnikkala S, Aaltonen K, Spillmann T, Vapalahti O. Survey of selected tick-borne diseases in dogs in Finland. Parasit Vectors. 2014;7:285.

47. Qurollo BA, Chandrashekar R, Hegarty BC, Beall MJ, Stillman BA, et al. A serological survey of tick-borne pathogens in dogs in North America and the Caribbean as assessed by Anaplasma phagocytophilum, A. platys, Ehrlichia canis, E. chaffeensis, E. ewingii and Borrelia burgdorferi speciesspecific peptides. Infect Ecol Epidemiol. 2014;4:246.

48. Little SE, Beall MJ, Bowman DD, Chandrashekar R, Stamaris J. Canine infection with Dirofilaria immitis, Borrelia burgdorferi, Anaplasma spp., and Ehrlichia spp. in the United States, 2010-2012. Parasit Vectors. 2014;7:257.

49. Pantchev N, Schnyder M, Globokar Vrhrovec M, Schaper R, Tsachev I. Current surveys of the seroprevalence of current surveys of Borrelia burgdorferi, Ehrlichia canis, Anaplasma phagocytophilum, Leishmania infantum, Babesia canis, Angiostrongylus vasorum and Dirofilaria immitis in Dogs in Bulgaria. Parasitol Res. 2015;114:117-30.

50. Chandrashekar R, Mainville CA, Beall MJ, O'Connor T, Eberts MD, Alleman $A R$, et al. Performance of a commercially available in-clinic ELISA for the detection of antibodies against Anaplasma phagocytophilum, Ehrlichia canis, and Borrelia burgdorferi and Dirofilaria immitis antigen in dogs. Am J Vet Res. 2010;71:1443-145.

51. Hernández JJ, Riojas VM, Avalos R, Zarate JJ, Zamora DE, Cantu MA, et al. Prevalencia de Anaplasma phagocytophilum en caninos de Monterrey. XXVI Congreso Nacional de Investigación en Medicina, 2011;www.medicina.uanl.mX.

52. Gordillo-Pérez G, Torres J, Solorzano-Santos F, Garduño-Bautista V, Tapia-Conyer R, Muñoz O. Seroepidemiologic study of Lyme's borreliosis in Mexico City and the Northeast of the Mexican Republic. Salud Publica Mex. 2003;45:351-5.

53. Bolio-Gonzalez ME, Rodriguez-Vivas RI, Sauri-Arceo CH, Gutierrez-Blanco E, Ortega-Pacheco A, Colin-Flores RF. Prevalence of the Dirofilaria immitis infection in dogs from Merida, Yucatan, Mexico. Vet Parasitol. 2007;148:166-9.

54. Manrique-Saide P, Bolio-González M, Sauri-Arceo C, Dzib-Florez S, Zapata-Peniche A. Ochleratus taeniorhynchus: a probable vector of Dirofilaria immitis in coastal areas of Yucatan, Mexico. J Med Entomol. 2008:45:169-71.

55. Cruz-Chan JV, Quijano-Hernandez I, Ramirez-Sierra MJ, Dumonteil E. Dirofilaria immitis and Trypanosoma cruzi natural co-infection in dogs. Vet J. 2010;186:399-401.

56. Caro-Gonzalez JA, Bolio-Gonzalez ME, Escobedo-Ortegon FJ, Manrique-Saide P, Rodríguez-Vivas RI, Rodríguez-Buenfil JC, et al. Prevalence of Dirofilaria immitis infection in dogs from Celestun, Mexico, using polymerase chain reaction test. Vector Borne Zoonotic Dis. 2011;11:193-6.

57. Nuñez-Ochoa L. Estudio de la seroprevalencia de Ehrlichia canis en México. AMMVEPE. 2003;14:83-5. http://www.imbiomed.com.mx.

58. Sosa-Gutierrez CG, Quintero Martinez MT, Gaxiola Camacho SM, Cota Guajardo S, Esteve-Gassent MD, Gordillo-Pérez MG. Frequency and clinical epidemiology of canine monocytic ehrlichiosis in dogs infested with ticks from Sinaloa, Mexico. J Vet Med. 2013;2013:797019.
59. Rodríguez-Viñas Rl, Albornoz RE, Bolio GM. Ehrlichia canis in dogs in Yucatan, Mexico: seroprevalence, prevalence of infection and associated factors. Vet Parasitol. 2005;127:75-9.

60. Jiménez-Coello M, Pérez-Osorio C, Vado-Solís I, Rodríguez Buenfil JC, Ortega-Pacheco A. Serological survey of Ehrlichia canis in stray dogs from Yucatan, Mexico, using two different diagnostic tests. Vector Borne Zoonotic Dis. 2009;9:209-12.

\section{Submit your next manuscript to BioMed Central and we will help you at every step:}

- We accept pre-submission inquiries

- Our selector tool helps you to find the most relevant journal

- We provide round the clock customer support

- Convenient online submission

- Thorough peer review

- Inclusion in PubMed and all major indexing services

- Maximum visibility for your research

Submit your manuscript at www.biomedcentral.com/submit
( Biomed Central 